\title{
Management of postoperative pain: experience of the Niamey National Hospital, Niger
}

This article was published in the following Dove Press journal:

Journal of Pain Research

4 December 2012

Number of times this article has been viewed

\author{
Maman Sani Chaibou' \\ Samuila Sanoussi \\ Rachid Sani ${ }^{2}$ \\ Nouhou A Toudou' \\ Hadjara Daddy' \\ Moussa Madougou' \\ Idrissa Abdou' \\ Habibou Abarchi \\ Martin Chobli ${ }^{3}$ \\ 'Department of Anesthesiology \\ and Intensive Care, ${ }^{2}$ Department \\ of Surgery, The Niamey National \\ Hospital, Niamey, Republic of Niger; \\ ${ }^{3}$ Department of Anesthesiology, \\ Hubert K Maga University Teaching \\ Hospital, Cotonou, Benin
}

Objective: The aim of this study was to evaluate the management of postoperative pain at the Niamey National Hospital.

Methods: A prospective study was conducted in the Department of Anesthesiology and Intensive Care at the Niamey National Hospital from March to June, 2009. Data collected included age, sex, literacy, American Society of Anesthesiologists (ASA) physical status classification, type of anesthesia, type of surgery, postoperative analgesics used, and the cost of analgesics. Three types of pain assessment scale were used depending on the patient's ability to describe his or her pain: the verbal rating scale (VRS), the numerical rating scale (NRS), or the visual analog scale (VAS). Patients were evaluated during the first 48 hours following surgery.

Results: The sample included 553 patients. The VRS was used for the evaluation of $72 \%$ of patients, the NRS for $14.4 \%$, and the VAS for $13.6 \%$. Of the VRS group, $33.9 \%, 8.3 \%$, and $2.1 \%$ rated their pain as 3 or 4 out of 4 at 12,24 , and 48 hours postoperatively, respectively. For the NRS group, $33.8 \%, 8.8 \%$, and $2.5 \%$ rated their pain as greater than 7 out of 10 at 12,24 , and 48 hours postoperatively, respectively. For the VAS group, $29.3 \%, 5.4 \%$, and $0 \%$ rated their pain as greater than 7 out of 10 at 12,24, and 48 hours postoperatively, respectively.

Conclusion: Postoperative pain assessment and management in developing countries has not been well described. Poverty, illiteracy, and inadequate training of physicians and other health personnel contribute to the underutilization of postoperative analgesia. Analysis of the results gathered at the Niamey National Hospital gives baseline data that can be the impetus to increase training in pain management and to establish standardized protocols.

Keywords: postoperative pain, pain scales, Niamey National Hospital

\section{Introduction}

The management of postoperative pain is a well-recognized problem for surgical teams. Interventions such as the use of multimodal analgesia, the preemptive use of analgesics and local anesthetics very early in surgery, and the standardization of procedures for pain management in postoperative units have been shown to improve pain management and surgical recovery. Despite this, deficiencies in pain management persist even in developed countries. ${ }^{1,2}$ Postoperative pain remains a major concern that has been shown to affect outcomes. Several methods for assessing pain have been identified, each with their advantages and disadvantages. The choice of method is based on the patient or unit protocol. Much research has focused upon discovering new analgesic drugs, developing more effective modes of drug administration, and the integration of multiple agents and techniques (multimodal analgesia) into patient care, but applying that research to practice has not always succeeded..$^{3-5}$
Correspondence: Maman Sani Chaibo Department of Anesthesiology and Intensive Care, Niamey National Hospital, Box 10337, Niamey, Republic of Niger Tel +2279477 7766

Email chaibou_msani@yahoo.fr 
In Niger, the management of postoperative pain remains problematic. ${ }^{6}$ The goal of this study was to evaluate the current methods of postoperative pain management at the Niamey National Hospital.

\section{Methods}

This prospective study was performed in the Department of Anesthesiology and Intensive Care at the Niamey National Hospital. Data was gathered from March through June 2009. The following variables were analyzed: age, sex, type of surgery, American Society of Anesthesiologists (ASA) classification, type of analgesia, and cost of analgesia. Patients were evaluated at intervals during the first 48 hours postsurgery with one of three scales. The scales were assigned depending upon the patient's comprehension: the verbal rating scale (VRS), the numerical rating scale (NRS), or the visual analog scale (VAS).

The VRS was presented to the patient as a series of descriptions, ranked and numbered, ranging from no pain (0), mild pain (1), moderate pain (2), and intense pain (3), to extremely intense pain (4).

The VAS was presented as a graduated line $10 \mathrm{~cm}$ long with designations from no pain at the left edge to maximum pain at the right. The patient was asked to position a cursor in the position that best represented the intensity of his or her pain (1-10). For the NRS, the patient was asked to rank his pain from 0 to 10 or 0 to 100 according to its intensity, with 0 representing the absence of pain and the maximum figure the worst pain imaginable. Data were analyzed with Epi Info $6^{\mathrm{TM}}$ (Centers for Disease Control and Prevention, Atlanta, GA).

\section{Results}

The study included 553 postoperative patients. Their average age was 39 years, ranging from 7 to 87 years. Males accounted for $53.2 \%$, with a male-to-female ratio of 1.14:1. Fifty-nine point three percent of our patients were illiterate. Orthopedic surgery was performed in $30.2 \%$, urogenital surgery in $30 \%$, and abdominal surgery in $21.9 \%$ (Table 1).

For anesthesia risk, $83.72 \%$ of patients were classified as ASA class 1 while $9.22 \%$ and $7.06 \%$ of patients were classified as ASA classes 2 and 3, respectively. General anesthesia was performed in $50.63 \%$ : spinal anesthesia was used in $48.28 \%$ and a plexus block in $1.08 \%$ of cases (Figure 1).

The most frequently used analgesics were tramadol (76.5\%), paracetamol (64.5\%), nonsteroidal anti-inflammatory
Table I Distribution of patients by the type of surgery

\begin{tabular}{lll}
\hline Type of surgery & Number of patients & Percentage \\
\hline Orthopedic & 167 & $30.2 \%$ \\
Urogenital & 166 & $30 \%$ \\
Abdominal & 121 & $21.9 \%$ \\
Ear-nose-throat & 35 & $6.3 \%$ \\
Neurosurgery & 22 & $4 \%$ \\
Thoracic & 12 & $2.2 \%$ \\
Proctology & 11 & $2 \%$ \\
Plastic & 10 & $1.8 \%$ \\
Others & 9 & $1.6 \%$ \\
Total & 553 & $100 \%$ \\
\hline
\end{tabular}

drugs (NSAIDS) (12.1\%), nefopam (2.3\%) and nalbuphine $(0.7 \%)$ (Figure 2$)$.

Multimodal analgesia was used in $53.32 \%$ of patients and $1 \%$ of patients received a regional block in addition to intravenous analgesia. The pain assessment was made by the VRS in $72 \%$ of patients ( $95 \%$ confidence interval [CI]: 68\%-75.6\%), by NRS in $14.4 \%$ (95\% CI: $11.7 \%-17.7 \%$ ), and by VAS in $13.6 \%$ (95\% CI: 10.9\%-16.8\%) (Figure 3). We noticed an increase in reported pain from 6 hours until 24 hours and then a gradual decline. Between 12 and 24 hours, the pain score diminished from moderate to severe, and was measured as weak after 36 hours.

Using the VRS assessment tool, 33.9\%, 8.3\%, and 2.10\% had level 3 (intense) or 4 (extreme) pain at 12, 24, and 48 hours, respectively.

Among the patients assessed by the NRS, 33.8\% reported a pain score greater than 7 out of 10 at 12 hours postoperatively. The number of patients reporting pain above 7 out of 10 decreased to $8.8 \%$ and $2.5 \%$ at 24 and 48 hours postoperation.

For the VAS group, $29.3 \%, 5.4 \%$, and $0 \%$ of patients reported pain greater than 7 out of 10 at 12,24, and 48 hours, respectively. The most frequently reported side effects of the use of analgesics were nausea and/or vomiting (36.62\%).

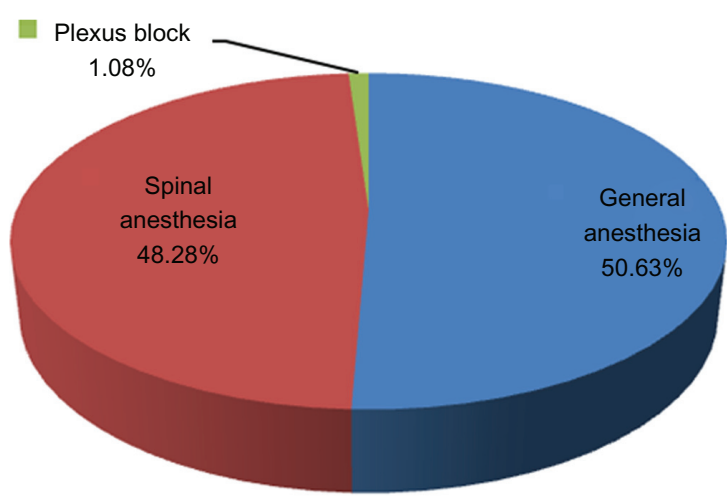

Figure I Distribution of patients by the type of anesthesia performed. 


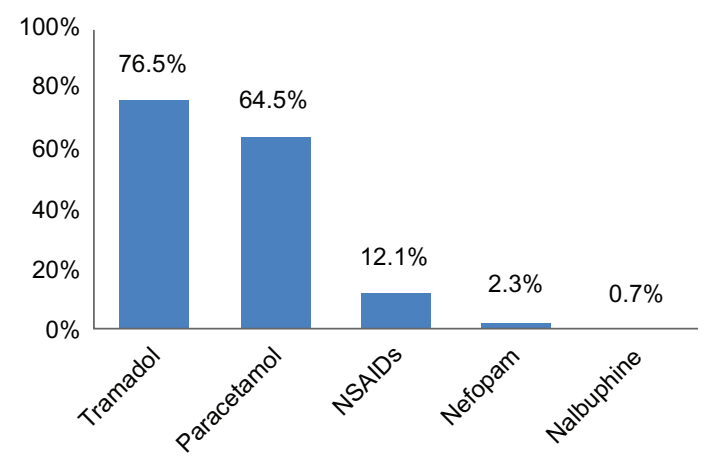

Figure 2 Distribution of patients by analgesics used.

Abbreviation: NSAIDS, nonsteroidal anti-inflammatory drugs.

The cost of analgesics ranged between US\$3.66 and \$54.82 depending on the agents utilized.

\section{Discussion}

The management of postoperative pain is a priority for the surgical team because inadequate treatment of pain is associated with postoperative complications and poor outcomes. ${ }^{7}$ At the Niamey National Hospital, postoperative care is provided by an anesthesia team composed of physicians and nurse anesthetists. Although each patient receives a postoperative follow-up that includes prescription of analgesics, barriers to effective pain management persist. In our series of 553 patients, there was a male predominance with a male-to-female ratio of 1.14:1. This is a typical ratio for surgical patients in Africa as noted in other studies. ${ }^{8}$ The average age of subjects was 39 years compared to an average of 41 years in a series from Nigeria and 51 and 52 years, respectively, in two studies from France. ${ }^{8,9}$ More than half $(53.3 \%)$ of patients were aged between 15 and 44 years and $59.3 \%$ were illiterate. These two statistics can be explained by the demographic of the population of Niger, where the median age is 15 years and literacy rates are low. ${ }^{10}$

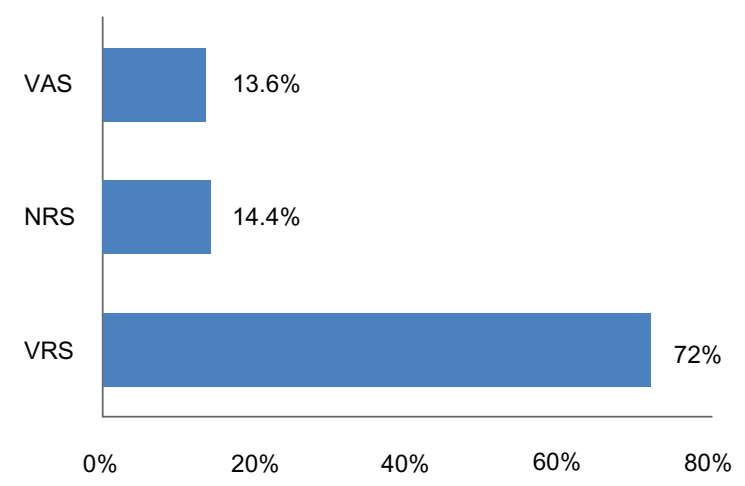

Figure 3 Distribution of patients according to the pain scale.

Abbreviations: NRS, numerical rating scale; VAS, visual analog scale; VRS, verbal rating scale.
In our series, orthopedic procedures were the most commonly performed surgeries and represented $30.2 \%$ of the sample. Urogenital surgery made up 30\% while abdominal surgery was performed in $21.9 \%$ of cases. In a study in France, Esteve et al also reported a preponderance of orthopedic surgery with $64.76 \%$ orthopedic and $34.58 \%$ abdominal surgery. ${ }^{11}$ Regional anesthesia was performed in almost half of the patients. In poorly resourced health systems like those in most of Africa, regional anesthesia, specifically spinal anesthesia, has a certain advantage because it requires little equipment and less medication and is easy for the anesthetist to perform. ${ }^{12,13}$

Only $1 \%$ of patients underwent a plexus block in spite of the fact that this technique offers several advantages including high patient satisfaction, reduced intraoperative blood loss, shortened length of stay, and lower incidence of postoperative nausea and vomiting. Reasons for low utilization of plexus nerve blocks include the lack of trained personnel and necessary equipment. ${ }^{14,15}$ The most commonly prescribed analgesic drugs were tramadol, paracetamol, and NSAIDS because these analgesics were available at the hospital. Nefopam and nalbuphine were minimally used because they are difficult to find in Niamey. While morphine is commonly used in Nigeria, it is rarely used in Niamey even though it is widely available. Its use is avoided mainly because of the fear of side effects such as respiratory depression, vomiting, urinary retention, and pruritis. ${ }^{8}$ This should not be a limiting factor given the quality of analgesia provided by the use of opioids postoperatively. Their careful use with appropriate monitoring can reduce the incidence of side effects and also lower the cost of postoperative analgesia. Combinations of agents were used as part of multimodal analgesia. Drugs commonly used in combination were paracetamol, tramadol, or nefopam along with NSAIDs. ${ }^{2,45,16}$ The Postoperative Analgesic Therapy Observational Survey in Europe shows use of multimodal analgesia improves local pain relief. ${ }^{17}$ Using multiple agents also allows for smaller doses of each, reducing the risk of adverse effects.

It is not common for practitioners in our hospital to use pain scales to assess postoperative pain. The intensity of postoperative pain is not noted in the postoperative patient record; this results in under appreciation of this sign and inadequate treatment by the medical and nursing staff.

In our study, we encountered many difficulties in using the VAS and NRS to assess pain in our patients who were, for the most part, uneducated. In some cases illiteracy and lack of medical knowledge combined to make understanding the concept of pain intensity a problem that forced 
us to use the VRS scale. Hence, the VRS assessment tool was used for $72 \%$, the NRS for $14.4 \%$, and the VAS for $13.6 \%$ of patients. In countries with higher literacy and education rates, other scales predominate in pain assessment studies. In a Senegalese review, the VRS was the least frequently used tool and a survey in France notes the use of tools in the descending order of NRS, VAS, and VRS. ${ }^{18,19}$ These results may be partly explained by the fact that patients received explanations of the pain assessment tools at the anesthetic preassessment interview in the French study.

All patients reported persistent pain in the postoperative period. Other studies have shown that pain management can be anticipated by the preoperative identification of patients and procedures prone to severe postoperative pain. ${ }^{20,21}$

Side effects of nausea and vomiting also caused discomfort to postoperative patients. This may be related to the high use of tramadol in our sample, which commonly causes nausea.,19,22 Expenses incurred for analgesia ranged from US\$3.66 to US\$54.82. It should be noted that in the Republic of Niger, families must pay for all surgical supplies, which makes poverty a limiting factor in the quality of analgesia in a country where the majority of the population is poor and uninsured. ${ }^{23}$

\section{Conclusion}

This study assessed the management of postsurgical pain at the Niamey National Hospital. Results of our data collection from 553 postoperative patients indicate that pain is often not well controlled postoperatively. Our data highlights a number of findings including a general lack of assessment with scales in the postoperative period, the limited use of local analgesia and plexus blocks and the lack of use of morphine as a postoperative analgesic. Improving the management of analgesia for postoperative patients requires systematic staff training of the surgical team and the creation of a standardized framework for the assessment and management of postoperative pain.

\section{Acknowledgments}

We acknowledge the efforts of Dr Susan Beebout, University of Iowa, Iowa City, IA and Dr Janet A Dewan, MS PhDc CRNA, Northeastern University, Boston, MA for the translation of this paper.

\section{Disclosure}

The authors report no conflicts of interest in this work.

\section{References}

1. Belbachir, Fletcher D, Larue F. Quality improvement and its evaluation for postoperative pain management. Ann Fr Anesth Reanim. 2009;28:e1-e12.

2. Fletcher D, Fermanian C, Mardaye A, et al. A patient-based national survey on postoperative pain management in France reveals significant achievements and persistent challenges. Pain. 2008;137:441-451.

3. Kapfer B, Alonsi P, Guignard B, Sessler DI, Chauvin M. Nefopam and ketamine comparably enhance postoperative analgesia. Anesth Analg. 2005;100:169-174

4. Fletcher D, Nègre I, Barbin C, et al. Postoperative analgesia with IV paracetamol and ketoprofen combination after disc surgery. Can J Anesth. 1997;44:479-485.

5. Jin F, Chung F. Multimodal analgesia for postoperative pain control. J Clin Anesth. 2001;13:524-539.

6. Diango D, Keita M, Bibiane A, et al. Evaluation de la prise en charge de la douleur au CHU GABRIEL TOURE du MALI [Evaluation of the management of postoperative pain in GABRIEL TOURE Teaching Hospital]. J Magh A Réa Urg. 2007;XV:298-302. French.

7. Jayr C. Retentissement de la douleur post opératoire et bénéfices attendus des traitements [Repercussions of postoperative pain. Expected the therapeutic benefits]. Ann Fr Anesth Réanim. 1998;17:540-554. French.

8. Ogboli-Nwasor E, Sule ST, Yusufu LM. Pattern of postoperative pain management among adult surgical patients in a low-resource setting. J Pain Res. 2012;5:117-120.

9. Mann C, Béziat C, Pouzeratte Y, et al. Programme d'assurance qualité de prise en charge de la douleur postopératoire: impact de la Conférence de consensus de la Sfar [Postoperative pain management quality assurance program: impact of the consensus conference of the French Society of anaesthesiology and intensive care]. Ann Fr Anesth Réanim. 2001;20:246-254. French.

10. Wikipedia [homepage on the Internet]. Niger. Available from: http:// en.wikipedia.org/wiki/Niger. [updated October 19, 2012]. Wikimedia Foundation, Inc. Accessed September 10, 2012.

11. Esteve M, Gaudé V, Alfonsi P, Brasseur L, Chauvin M. Analgésie post opératoire par PCA morphine IV: Evaluation sur plus d'un an de suivi d'activité [PCA morphine-based operative analgesia: more than one year follow-up activity evaluation]. Ann Fr Anesth Réanim. 1997;16: 748. French.

12. Carpentier JP, Banos JP, Brau R, et al. Pratique et complications de la rachianesthésie en milieu tropical africain [Practice and complications of spinal anaesthesia in African tropical countries]. Ann Fr Anesth Réanim. 2001;20:16-22. French.

13. Adnet P, Diallo A, Sanou J, et al. Pratique de l'anesthésie par les infirmier(e)s en Afrique francophone subsaharienne [Anaesthesia practice by nurse anaesthetists in French speaking sub-Saharan Africa]. Ann Fr Anesth Réanim. 1999;18:636-641. French.

14. Cuvillon P, Ripart J, Debureaux S, et al. Analgésie postopératoire par cathéter fémoral après fracture du col du fémur chez les personnes agées: étude prospective randomisée [Analgesia after hip fracture repair in elderly patients: the effect of a continuous femoral nerve block: a prospective and randomised study]. Ann Fr Anesth Réanim. 2007;26:2-9. French.

15. Sanou I, Vilasco B, Obey A, et al. Évolution de la démographie des praticiens d'anesthésie en Afrique francophone au sud du Sahara [Time course of the demography of anaesthetists and nurse anaesthetists in French-speaking sub-Saharan countries]. Ann Fr Anesth Réanim. 1999;18:642-646. French.

16. Sohita D. Tramadol/paracetamol fixed-dose combination. A review of its use in the management of moderate to severe pain. Clin Drug Investig. 2010;30:711-738.

17. Benhamou D, Viel E, Berti M, et al. Enquête européenne sur la prise en charge de la douleur et de l'analgésie postopératoires (PATHOS): les résultats français [Postoperative Analgesic Therapy Observational Survey (PATHOS): Study on postoperative pain management in Europe: French data]. Ann Fr Anesth Réanim. 2008;27:664-678. French. 
18. Diouf E, Ndiaye PI, Ndoye MD, et al. Evaluation des connaissances des praticiens sur la prise en charge de la douleur postopératoire au Sénégal [Evaluation of knowledge of the experts on the treatment of postoperative pain in Senegal]. Rev Afr Anesth Méd Urg. 2011;16:22-29. French.

19. Fletcher D, Mardaye A, Fermanian C, Aegerter P, Ecoffey C, Comité douleur ALR (Garchier). Evaluation des pratiques sur l'analgésie post opératoire [A national survey of postoperative pain management in France: influence of type of surgical centres]. Ann Fr Anesth Réanim. 2008;27:700-708. French.

20. Langlois M, Fletcher D. Douleur postopératoire [Postoperative pain]. In: Anesthésie Réanimation Chirurgicale. 3rd ed. Paris: Médecine Sciences Flammarion; 2003. French.
21. Kalkman CJ, Visser K, Moen J, et al. Preoperative prediction of severe postoperative pain. Pain. 2003;105:415-423.

22. Scott LJ, Perry CM. Tramadol: a review of its use in perioperative pain. Drugs. 2000;60:139-176.

23. International Human Development Indicators [webpage on the Internet]. United Nations Development Programme; 2011. Available from: http://hdrstats.undp.org/en/indicators/default.html. Accessed September 10, 2012
Journal of Pain Research

\section{Publish your work in this journal}

The Journal of Pain Research is an international, peer-reviewed, open access, online journal that welcomes laboratory and clinical findings in the fields of pain research and the prevention and managemen of pain. Original research, reviews, symposium reports, hypothesis formation and commentaries are all considered for publication.

\section{Dovepress}

The manuscript management system is completely online and includes a very quick and fair peer-review system, which is all easy to use. Visit http://www.dovepress.com/testimonials.php to read real quotes from published authors. 